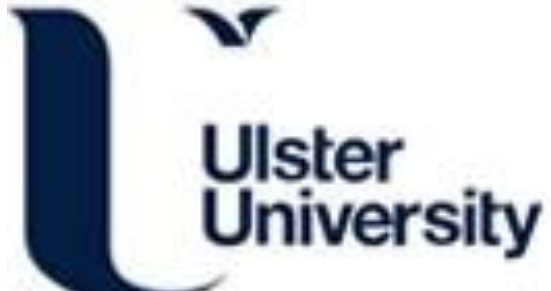

\section{Using a Personal-Disclosure Mutual-Sharing Approach to Deliver a Team-Based Mindfulness Meditation Program to Enhance Cohesion}

Piasecki, P., Loughead, T. M., Paradis, K., \& Munroe-Chandler, K. (2021). Using a Personal-Disclosure MutualSharing Approach to Deliver a Team-Based Mindfulness Meditation Program to Enhance Cohesion. The Sport Psychologist, 35(1), 22-29. https://doi.org/10.1123/tsp.2019-0116

Link to publication record in Ulster University Research Portal

\section{Published in:}

The Sport Psychologist

Publication Status:

Published online: 09/02/2021

DOI:

10.1123/tsp.2019-0116

\section{Document Version}

Author Accepted version

\section{General rights}

Copyright for the publications made accessible via Ulster University's Research Portal is retained by the author(s) and / or other copyright owners and it is a condition of accessing these publications that users recognise and abide by the legal requirements associated with these rights.

\section{Take down policy}

The Research Portal is Ulster University's institutional repository that provides access to Ulster's research outputs. Every effort has been made to ensure that content in the Research Portal does not infringe any person's rights, or applicable UK laws. If you discover content in the Research Portal that you believe breaches copyright or violates any law, please contact pure-support@ulster.ac.uk. 
$4 \quad$ Using a Personal-Disclosure Mutual-Sharing Approach to Deliver a Team-Based Mindfulness 


\section{Abstract}

7 In an effort to increase perceptions of cohesion among intercollegiate soccer players, a team-

8 based mindfulness meditation program was undertaken. This team-building program was

9 delivered by using a personal-disclosure mutual-sharing (PDMS) approach. A total of 31 female

10 intercollegiate soccer players from two teams participated. One team $(n=17)$, assigned to the

11 intervention condition, was a Canadian Intercollegiate team (U Sports), while the other team $(n=$

12 14) who served as the control condition, was an American Intercollegiate team (NCAA, Division

13 II). Participants completed a measure of cohesion (Group Environment Questionnaire) pre- and

14 post-intervention. The eight-week team-based mindfulness meditation program resulted in

15 significantly higher perceptions of social cohesion for the intervention group compared to the

16 control group at post-intervention. However, there were no significant differences for task

17 cohesion between the intervention and control group at post-intervention. Using PDMS seems a

18 viable approach by which to deliver a team-based mindfulness meditation program to enhance a 19 team's social cohesion. 
Using a Personal-Disclosure Mutual-Sharing Approach to Deliver a Team-Based Mindfulness Meditation Program to Enhance Cohesion In sport, numerous teams have been considered dynasties; the New York Yankees in

23 baseball, the Montreal Canadiens in hockey, the Chicago Bulls in basketball, and Manchester

24 United in soccer. Moreover, they have anecdotally attributed their success to having strong team 25 unity or team cohesion. Cohesion is viewed in such high regard due to the fact that it is a key attribute of successful groups across many contexts including work, exercise, military, and sport

27 (Carron, Brawley, \& Widmeyer, 1998; Carron \& Eys, 2012; Martin, Paradis, Eys, \& Evans, 2013). From an empirical perspective, the importance of cohesion comes not only from its association with performance and team success (Carron, Bray, \& Eys, 2002; Carron, Colman, Wheeler, \& Stevens, 2002), but also in its positive relationship with variables such as satisfaction, passion, and intention to return (Paradis \& Loughead, 2012; Paradis, Martin, \& Carron, 2012; Spink, Wilson, \& Odnokon, 2010). With cohesion being an essential part of sport teams, it is defined as a dynamic emergent state (McEwan \& Beauchamp, 2014) "reflected in the tendency for a group to stick together and remain united in the pursuit of its instrumental objectives and/or for the satisfaction of member affective needs" (Carron et al., 1998; p. 213). which to develop cohesion (Paradis \& Martin, 2012). The present study operationalized teambuilding as the process of promoting a sense of cohesion that enables the team to work more smoothly and effectively (Brawley \& Paskevich, 1997; Widmeyer \& Ducharme, 1997). In order to help guide team-building interventions, Carron and Spink (1993) forwarded an applied team-

42 building model comprised of factors believed to enhance perceptions of cohesion. This is a linear 
43 model consisting of inputs, throughputs, and outputs. The inputs include team environment (e.g.,

44 team togetherness, team distinctiveness) and team structure (e.g., team norms, leadership, roles).

45 These two factors are hypothesized to influence the throughput of team processes (e.g., team

46 interaction and communication, team sacrifices), which then impacts the output of cohesion. For

47 the purposes of the current study, the focus was on the team processes of team interaction and

48 communication to increase perceptions of cohesion.

To help foster team interaction and communication, the method used in the current study

50 was personal-disclosure mutual-sharing (PDMS) (Crace \& Hardy, 1997; Dunn \& Holt, 2004;

51 Holt \& Dunn, 2006). PDMS is a team-building approach that invites individuals to disclose

52 stories and information to teammates (Evans, Slater, Turner, \& Barker, 2013). This type of team-

53 building approach allows athletes to cultivate greater appreciation for their teammates, such as

54 understanding their values, beliefs, attitudes, and personal motives (Hirsch, 1992). That is,

55 collaborative personal disclosure matched with mutual sharing provides group members an

56 opportunity for empathic responses and can foster enhanced understanding and appreciation of

57 one another's experiences (Dryden, 2006). PDMS, as a team-building intervention, has not only

58 increased perceptions of cohesion but also increased team functioning, collective efficacy, and

59 trust in teammates, as well as greater self and teammate awareness and understanding (Barker,

60 Evans, Coffee, Slater, \& McCarthy, 2014; Dunn \& Holt, 2004; Evans et al., 2013; Holt \& Dunn,

61 2006; Pain \& Harwood, 2009; Windsor, Barker, \& McCarthy, 2011). For instance, Pain and

62 Harwood (2009) found their PDMS intervention led to increases in cohesion, communication,

63 trust, and confidence in teammates. Similarly, Dunn and Holt (2004) found enhanced cohesion,

64 improved confidence in teammates, and better understanding of self and others following one 
PDMS session. Players reported feelings of enhanced closeness and connectedness coupled with feelings of increased collective efficacy, and invincibility (Dunn \& Holt, 2004).

The PDMS approach was the means by which a team-based mindfulness meditation program was delivered in the current study. A team-based mindfulness meditation program was selected based on Cleirigh and Greaney's (2015) contention that mindfulness may positively influence cohesion since the former is related to reduced social anxiety, increased acceptance, and emotional regulation. Consequently, interpersonal attraction (an element of cohesion) is enhanced due to the effects of mindfulness creating an atmosphere that is more welcoming and less threatening thereby allowing individuals to view their group members with openness and receptivity.

To test their contention, Cleirigh and Greaney (2015) randomized 34 undergraduate students from an applied psychology course into either a mindfulness or control condition. Participants in the mindfulness condition received a 10-minute audio recording consisting of an introduction to mindfulness along with two exercises to help participants become mindful of their breath and emotions. Participants in the control condition listened to two educational excerpts. Next, all participants were placed in groups of four within their respective experimental condition and completed a hypothetical group task consisting of a winter survival activity whereby the groups ranked the items (e.g., compass, axe) in order of importance for the group's survival. Following the completion of the task, all participants completed a cohesion inventory measuring a sense of belonging and feelings of group morale. It was found that participants in the mindfulness intervention condition scored higher in cohesion than those in the control condition. 
Baltzell, Carabello, Chipman, and Hayden (2014) conducted a qualitative study

examining mindfulness with a Division I women's soccer team. All team members $(N=19)$ received 12 mindfulness sessions (completed in a team setting) over six weeks. At the end of the six-week intervention, seven of the 19 athletes participated in individual interviews to discuss their experiences with the intervention. Within the results, one of the higher order themes related to the impact of the intervention on the team. In particular, one of the mindfulness intervention activities was related to having caring thoughts about the self and team. In discussing this activity, the participants indicated that these thoughts made the team feel more united, inferring a strengthening of the team's cohesion.

Although both of the aforementioned studies suggest that mindfulness is positively related to cohesion, caution should be used when interpreting the findings. First, in the Cleirigh and Greaney (2015) study, there were no baseline cohesion scores to control for whether cohesion actually changed as a result of the intervention. Second, in both studies (Baltzell et al., 2014; Cleirigh \& Greaney, 2015), participants completed the mindfulness sessions in a group setting, however, there were limited opportunities to discuss aspects of the mindfulness sessions as a group. If team-based mindfulness programs are going to be used to enhance cohesion, then it would be important that opportunities for the participants to interact and discuss with one another exist. A PDMS approach offers the opportunity, through interpersonal interaction, to impact relationship functioning such as feelings of closeness, relatedness, acceptance, and satisfaction which are key attributes of mindfulness training (Carson, Carson, Gil, \& Baucom, 2004). Kabat-Zinn (2003) defined mindfulness as "the awareness that emerges through paying attention on purpose, in the present moment, and non-judgmentally to the unfolding of experience moment by moment" (p. 145). Put simply, mindfulness is the state of being attentive 
110

111

112

113

114

115

116

117

118

119

120

121

122

123

124 125 2016).

126

127

128

129

130

131

132

to and aware of what is taking place in the present moment, attending to one's internal experiences as they unfold in one's life, and the ability to manage these experiences within oneself (Brown \& Ryan, 2003).

Various researchers have shown that athletes who participate in mindfulness training developed a better acceptance of external events and are able to better focus on internal information (Gooding \& Gardner, 2009; John, Verma, \& Khanna, 2011). For example, mindfulness training allowed athletes to reduce distraction around them and be more focused on relevant moment-to-moment information to optimize performance (Bernier, Thienot, Cordon, \& Fournier, 2009). Mindfulness has also been related to decreasing stress, depression, anxiety, and rumination (Li, Yuan, \& Zhang, 2016; Remmers, Topolinski, \& Koole, 2016), along with increased observing and non-judging, where the individual's attention is heightened to observe their present moment without judging their experience (Labelle, Campbell, Faris, \& Carlson, 2015). Additionally, college students who participated in a mindfulness meditation program reported enhanced self-control and vitality, along with better regulation of emotions and suppression of thoughts (Canby, Cameron, Calhoun, \& Buchanan, 2015; MacDonald \& Baxter,

The current study adopted the mindfulness program, 'Koru', designed for university-aged students (Rogers \& Maytan, 2012). The word Koru is derived from the New Zealand Maori culture which symbolizes balanced growth, new life, and harmony. Koru is a training program that specifically targets young adults, teaching them mindfulness meditation that includes several mind-body skills, such as abdominal breathing and guided imagery. Compared to other mindfulness-based interventions (e.g., Mindful Sport Performance Enhancement, Kaufman, Glass, \& Pineau, 2018; Mindfulness-Acceptance-Commitment Approach, Gardner \& Moore, 
133 134

\section{Participants}

2004; Mindfulness Meditation Training for Sport, Baltzell \& Akhtar, 2014; Berlin Mindfulnessbased Training for Athletes, Jekauc, Kittler, \& Schlagheck, 2017), Koru is intentionally delivered in a group setting to capitalize on interactions amongst participants, which aligns with PDMS. Participants are provided with a space for open group discussion, sharing of information, and improved communication. As noted by Greeson, Juberg, Maytan, James, and Rogers (2014), Koru provides participants with "a greater sense of connection through common humanity and less isolation" (p. 231). As a result, an important aspect of Koru is the group focused nature of the mindfulness sessions where chairs are arranged in a circle to encourage inclusion and capitalize on peer interactions, which is a fundamental component of PDMS. That is, PDMS allows participants to develop a better understanding of their teammates, cultivating trust, mutual respect, and support (Pain \& Harwood, 2009), leading to a better functioning environment (Evans et al., 2013) and ultimately providing a positive environment for enhancing cohesion. Therefore, the purpose of the present study was to explore the effects of a team-based mindfulness meditation program on perceptions of cohesion using PDMS, where participants shared their current experiences with their mindfulness practices with their teammates. Using a quasi-experimental design, it was hypothesized that individuals receiving the team-based mindfulness meditation training program intervention would have stronger perceptions of cohesion compared to individuals in the control condition following the intervention.

\section{Method}

Thirty-one intercollegiate female soccer players from two teams participated in the current study. One team and its players $(n=17)$ from a U Sports Canadian university were assigned to the intervention condition. The second team and its players $(n=14)$ from a Division 
II NCAA American university served as the control condition. The two teams were selected since they are similar in terms of competition level (ESPN, 2007) and the season was equivalent in terms of the number of games played. The average age of the participants was 18.90 years (SD $=1.36)$, had been on their current team for an average of 1.88 years $(\mathrm{SD}=1.05)$, and had been playing soccer for an average of 13.1 years $(\mathrm{SD}=3.29)$. At the end of the regular season, the intervention team had a win-tie-loss record of 4-5-8 for a winning percentage of $33.3 \%$. The control team was 2-0-16 for a winning percentage of $11.1 \%$.

\section{Study Conditions}

Intervention condition. The athletes in the intervention condition were asked to complete a questionnaire package to assess cohesion pre- and post-intervention. Rogers and Maytan's (2012) Koru approach for teaching mindfulness to university students was adapted and implemented as the intervention for the current study. There were eight weekly Koru team sessions lasting between 45 to 55 minutes in duration. During each team session, athletes learned and practiced mindfulness meditation and one or two mind-body skills (see Table 1 for a brief overview of the program). Each team session began with a "check-in," which gave participants an opportunity to share any struggles they were facing when completing the mindfulness meditation and/or any obstacles they currently were dealing with in sport or life. Additionally, the "check-in" served as an opportunity for participants to share any successes. The "check-in" exercise was formatted using a PDMS approach that helped to foster an appreciation of team members' values, beliefs, attitudes, and personal motives (Hirsch, 1992). In addition to the weekly team sessions, the Koru program required each participant to individually practice meditation for a minimum of 10 minutes daily. In order to assess participant adherence and engagement, players completed a daily meditation log, which included documenting two things 
179 for which the participant felt grateful. Participants were also required to attend the weekly team 180 sessions.

Control condition. The athletes in the control condition were asked to complete a

182 questionnaire package to assess cohesion twice during the season; once prior to the start of the

183 regular season and once near the end of the regular season. Throughout the season, the athletes in

184 this condition received no additional support from any sport psychology consultant, including 185 members of the research team.

186 Measures

All participants, regardless of condition, completed the 18-item Group Environment Questionnaire (GEQ; Carron, Widmeyer, \& Brawley, 1985) at two time points (pre- and post189 intervention). The GEQ assesses perceptions of cohesion across four dimensions: Individual Attractions to Group-Task (ATG-T; 4 items), Individual Attractions to Group-Social (ATG-S; 5

191 items), Group Integration-Task (GI-T; 4 items), and Group Integration-Social (GI-S; 5 items). 192 Sample items from each dimension are: ATG-T, "I do not like the style of play on this team;" 193 ATG-S, "For me, this team is one of the most important social groups to which I belong;" GI-T, 194 "Our team is united in trying to reach its goals for performance;" GI-S, "Our team would like to 195 spend time together in the off season." Respondents are asked to rate each item on a 9-point 196 Likert scale anchored at 1 (strongly disagree) and 9 (strongly agree). It should be noted that 12 197 of the 18 items from the GEQ are negatively worded and need to be reversed scored. Thus, 198 higher scores represent stronger perceptions of cohesion. Evidence for concurrent, predictive, 199 construct, and factorial validity of the GEQ has been demonstrated (Brawley, Carron, \& 200 Widmeyer, 1987; Eys \& Brawley, 2018; Martin et al., 2013).

\section{Procedure}


Ethical approval for the study was obtained from the university's research ethics board.

203

204

205

206

207

208

209

210

211

212

213

214

215

216

217

218

219

220

221

222

223

224

All data were collected using Qualtrics software. Participants had the opportunity to be entered into a draw to win one of two $\$ 50$ Amazon gift cards. The head coach of the intervention team approached members of the research team two months prior to the start of the competitive season to ask if we were interested in delivering a season long team-building program. The research team agreed to assist the soccer team with the primary investigator being the individual responsible for delivering the team-building program. A PDMS approach was selected as the method for team-building based on the notion that this type of approach is useful in increasing perceptions of cohesion (Dunn \& Holt, 2004; Holt \& Dunn, 2006; Pain \& Harwood, 2009), and that mindfulness meditation programs have been shown to enhance cohesion (Baltzell et al., 2014; Cleirigh \& Greaney, 2015). A meeting was scheduled with the participants of the intervention group to outline the mindfulness-based team-building intervention. All of the athletes consented to participate in the study. The athletes in the intervention condition were informed that they would be involved in a season long mindfulness meditation team-building program using a PDMS approach and would complete the GEQ (Carron et al., 1985) two times during the season; a baseline measure prior to the start of the regular season (Time 1), and postintervention that occurred near the end of the regular season (Time 2). The primary researcher had the requisite training through a formalized workshop training program to teach mindfulness (Ahlin \& Kjellgren, 2016) and team-building workshops. Therefore, the first author was responsible of implementing and monitoring the athletes in the mindfulness meditation teambuilding program. Athletes in the control condition completed the GEQ at the same two time points as the athletes in the intervention condition.

Results 
A summary of the descriptive statistics can be found in Table 2. Data were analyzed using SPSS 24 software (IBM SPSS Predictive Analytics, Chicago, IL). Given that intact teams were used (i.e., one team served as the intervention group and the other as the control group), Schumacker (2016) recommends the use of a MANCOVA since the "purpose of MANCOVA is to adjust post means for initial differences in groups (generally based on pretest measures of intact groups, where random selection and random assignment to group was not possible)" (p. 84). Consequently, the dependent variables were the post-intervention (Time 2) dimensions of cohesion. The fixed factor was condition (intervention vs. control) and the covariates were the baseline (Time 1) dimensions of cohesion. The results yielded a significant multivariate effect: Pillai's trace $F(4,22)=6.04, \eta^{2}=.52, p<.05$, and univariate analyses demonstrated that the groups differed significantly in perceptions of cohesion on the two social dimensions, with the intervention group holding greater perceptions than the control group: ATG-S, $F(1,25)=3.90$, $\eta^{2}=.14, p<.05, d=0.82$, and GI-S, $F(1,25)=19.48, \eta^{2}=.44, p<.05, d=1.26$. There were no significant differences between the groups on the two task dimensions of cohesion: (ATG-T, $F(1,25)=.013, \eta^{2}=.00, p=.91 ;$ GI-T, $\left.F(1,25)=.65, \eta^{2}=.03, p=.43\right)$.

\section{Discussion}

The purpose of the present study was to examine the effects of a PDMS influenced teambased mindfulness meditation team-building program on perceptions of cohesion. It was hypothesized that participants in the intervention condition would have stronger perceptions of cohesion following the 8-week program compared to participants in the control condition. It is important to note the novelty of using the PDMS framework as a means by which a team-based mindfulness meditation team-building program was delivered. Therefore, the current study is the first of its kind in the realm of sport to use a team-based approach. To date, researchers have 
248 investigated individual-based mindfulness meditation programs within sport and found the

249 programs to influence individual outcomes such as performance (e.g., Baltzell \& Akhtar, 2014;

250 Kaufman et al., 2018), stress (Goodman, Cashdan, Mallard, \& Schumann, 2014), injury risk

251 (Ivarsson, Johnson, Andersen, Fallby, \& Altemyr, 2015), psychological well-being, life

252 satisfaction, and positive affect (Baltzell \& Akhtar, 2014). However, the present study expanded

253 upon the extant literature to examine a team-based outcome in the form of cohesion.

The current study contributes empirical evidence to the literature that a team-based

255 mindfulness meditation program, delivered through PDMS, can positively influence perceptions

256 of social cohesion within sport (Baltzell, Chipman, Hayden, \& Bowman, 2015; Cleirigh \&

257 Greaney, 2015). In particular, the current study showed that the intervention group receiving the

258 mindfulness meditation program had significantly higher perceptions of social cohesion (i.e.,

259 ATG-S, GI-S) compared to the control group post-intervention. The current study's findings can

260 be explained by Crace and Hardy's (1997) notion that mutual understanding is a cornerstone of

261 the team-building process. Additional PDMS research has reported athletes sharing personal

262 stories leads to feelings of closeness, understanding, and connectedness within a team setting,

263 outcomes that often complement social cohesion (Dunn \& Holt, 2004; Holt \& Dunn, 2006). The

264 results of the present study also support Tziner, Nicola, and Rizac's (2003) contention that

265 perceptions of social cohesion may evolve when collaborative interactions between team

266 members are emphasized through the use of task strategies (i.e., mindfulness meditation).

267 However, the intervention did not significantly impact two dimensions of task cohesion

268 (i.e., ATG-T, GI-T). These findings in regard to task cohesion are similar to previous research

269 conducted with PDMS-based interventions in that task cohesion was not enhanced (e.g., Dunn \&

270 Holt, 2004; Pain \& Harwood, 2009). For the current study, this could be due to the length of the 
271 intervention (i.e., 8-weeks) and/or the nature of the mindfulness intervention and the "check-in"

272 portion of each session, which provided participants an opportunity to share their challenges or

273 breakthroughs regarding their mindfulness practice. In terms of the null finding concerning task

274 cohesion, Windsor et al. (2011), using a PDMS approach to team-building, measured cohesion

275 using the GEQ pre- and post-intervention and found no significant changes to either task and

276 social cohesion. Windsor et al. (2011) attributed their null findings to the length of their

277 intervention program, which was four weeks in duration. Yet, in terms of social cohesion, Carson

278 et al. (2004) found that a mindfulness-based relationship enhancement intervention was

279 efficacious in enriching relationship functioning, showing improvement in an individual's

280 acceptance of their partner. Consequently, the results of our intervention are aligned with the

281 characteristics of team-building interventions in sport that use a combination of omnibus and

282 socially oriented approaches (Martin, Carron, \& Burke, 2009).

Another possible explanation to why task cohesion was not influenced by the intervention

284 program may be related to the performance standards of the intervention team in the current

285 study. It is important to note that the intervention team was quite successful in the season prior to

286 partaking in the study (i.e., 11 wins, 3 loses, and 8 ties) as they qualified for the provincial

287 championship. As such, they set high expectation for themselves in the subsequent season, which

288 included the goal of qualifying for the national championship tournament. Unfortunately, this

289 goal was not met with the team not qualifying for playoffs and finishing with a losing record.

290 From the first author's observation, the team seemed discouraged and frustrated towards the end

291 of the intervention regarding the team's on-field performance. Thus, it is not surprising that task

292 cohesion for the intervention team was elevated at baseline (coming off a successful season full

293 of high expectations) as opposed to post-intervention (having an unsuccessful season that 
294 included a losing record and not qualifying for the post-season). We attribute the reduced task 295 cohesion to this situational occurrence.

Considering the well-established cohesion-performance relationship (Carron, Colman, et

297 al., 2002), we know that as performance drops, so does cohesion (and vice versa). Carron,

298 Colman, et al. (2002) found a large effect for the cohesion-performance relationship based on

299 objective measures (e.g., percentage of possible points, wins/losses) and this effect is greater in

300 females. In the current study, we had two female teams that both had losing seasons (i.e.,

301 winning percentages below 50\%). In fact, the descriptive statistics showed, for the most part, that

302 both the intervention and control groups had a reduction in cohesion from pre- to post-

303 intervention as their respective on-field results declined throughout the season and thus were

304 unable to achieve their goals. However, cohesion was better maintained or salvaged in the

305 experimental condition compared to the control condition. Therefore, it is surmised that these

306 less than desirable seasons were generally associated with lower perceptions of cohesion for both

307 the intervention and control conditions. However, the results of the current study are encouraging

308 in that a PDMS approach to team-building using a group-based meditation program can help

309 mitigate these effects for social cohesion. That is, given that performance can influence cohesion,

310 the sub-optimal level of performance in the intervention group further provides confidence in the

311 effectiveness of the intervention, as it was unlikely that performance was contributing much, if

312 anything, to the cohesiveness of the team. In this case, cohesion may have been facilitating better

313 resistance to the group disruption (e.g., Brawley, Carron, \& Widmeyer, 1988) experienced from

314 a losing season in the intervention group. It is also, therefore, important to determine other

315 moderating influences that may have impacted the task cohesion and team performance

316 relationship that were unaccounted in the current study such as role involvement (Eys, Carron, 
317 Beauchamp, \& Bray, 2005), collective efficacy (Paskevich, Brawley, Dorsch, \& Widmeyer, 318 1999), and team conflict (Paradis, Carron, \& Martin, 2014a). For example, Paradis, Carron, and 319 Martin (2014b) found that task and social conflict were significantly negatively related to all four 320 dimensions of cohesion. Likewise, Leo, Gonzalez-Ponce, Sanchez-Miguel, Ivarsson, and Garcia321 Calvo (2015) found that perceptions of cohesion and conflict fluctuated with performance and in 322 turn predicted the different levels of collective efficacy over time among professional soccer 323 players. The influence of such variables warrants further study and should be considered for 324 inclusion in future team-building research. Inclusion of team-building activities that focus on 325 role involvement and collective efficacy have shown to also be effective in improving 326 perceptions of cohesion (Martin et al., 2009). The results of the current study also raise interesting insights into the dynamic nature of cohesion, which has been widely advanced in theoretical and conceptual writings (Carron \& Eys, 329 2012). Despite being largely untested empirically, Dunlop, Falk, and Beauchamp (2013) assessed the dynamic nature of cohesion and found that social cohesion changed more over time 331 while task cohesion remained more stagnant; thus, supporting the current study's findings. Sport 332 provides an ideal environment where interactions and relationships are encouraged (Eys, Bruner, $333 \&$ Martin, 2018). Those looking to develop and enhance social relationships in their teams 334 should keep this in mind when implementing a team-building program to promote cohesion 335 (Martin, Bruner, Eys, \& Spink, 2014). Although the results of the current study contribute to the literature in terms of the 337 usefulness of a team-based mindfulness program, delivered using a PDMS approach, as an 338 effective team-building tool to increase social cohesion, there is a need for continued research in 339 this area. First, it is recommended that researchers implement a team-based mindfulness 
340

341

342

343

344

345

346

347

348

349

350

351

352

353

354

355

356

357

358

359

360

361

362

meditation training program using a variety of sports and with male athletes to increase generalizability. Second, given that there was no significant increase in task cohesion, it would be useful for researchers to conduct a qualitative study (e.g., semi-structured interviews, focus groups) to determine how a losing team performance over a season impacts perceptions of cohesion. Third, only one group variable — cohesion — was examined in the current study. It would be worthwhile to consider other group dynamics constructs, such as peer friendships, communication, and collective efficacy, when using a team-based mindfulness meditation training program. Fourth, it should be noted that there were differences between the intervention and control groups in terms of winning percentages that may have impacted perceptions whereby the intervention group had a higher winning percentage than the control group. Nonetheless, both groups had losing seasons (i.e., winning percentages below 50\%). Regardless of the winning percentage, losing in sport is related to negative emotions in athletes including increases in stress and humiliation (Compton \& Compton, 2014). Although the differences in winning percentages may have influenced perceptions of cohesion, future research should move beyond winning percentages as an explanation of the cohesion-performance relationship. As Jones, Mellalieu, and James (2004) pointed out a more comprehensive measure of successful (or unsuccessful) performances are performance indicators. In the sport of soccer, examples of performance indicators may include turnovers won as a percentage of the total turnovers made by both teams or time in possession of the ball. Therefore, researchers are encouraged to examine the influence of these performance indicators on cohesion. Lastly, future researchers should design a study with the addition of an attentional-control group. Allowing the attentional-control group to be a part of PDMS (minus the mindfulness meditation) would prove valuable in determining further the intervention's effectiveness. 
The current study also offers applied implications for coaches and sport psychology consultants. Using PDMS to deliver a mindfulness meditation training can be used as a team-

365 building intervention to foster perceptions of social cohesion. This gives coaches and sport 366 psychology consultants another tool to use in their practice to improve the social relationships 367 between teammates. Enhancing social cohesion remains an essential target outcome of team368 building (Martin et al., 2009) given the well-established social cohesion-performance 369 relationship (Carron, Colman, et al., 2002).

370 In summary, the current study was the first of its kind to explore the variables of cohesion 371 in the context of sport using PDMS to deliver a team-based mindfulness meditation training 372 program. Using a PDMS framework to deliver a team-based mindfulness meditation training 373 program can positively influence social cohesion. The current study's methodology provided 374 insight into the effectiveness of an 8-week team-based mindfulness meditation training program, 375 as 8-week programs have shown to be effective (Martin et al., 2009) and also allowed for the 376 adequate time for changes in cohesion to emerge (Dunlop et al., 2013; Windsor et al., 2011). 377 Further research pertaining to the delivery of a team-based mindfulness meditation training 378 program through PDMS to improve cohesion is warranted to confirm the findings from the 379 present study and to further advance the team-building literature in sport psychology. 


\section{References}

Ahlin, K., \& Kjellgren, A., (2016). Prerequisites for teaching mindfulness and meditation, experienced teachers from different traditions share their insights. Journal of Yoga \& Physical Therapy, 6, 1-8.

Baltzell, A., \& Akhtar, V. L. V. (2014). Mindfulness meditation training for sport (MMTS) intervention: Impact of MMTS with Division I female athletes. The Journal of Happiness \& Well-Being, 2, 160-173.

Baltzell, A., Caraballo, N., Chipman, K., \& Hayden, L. (2014). A qualitative study of the mindfulness meditation training for sport: Division I female soccer players' experience. Journal of Clinical Sport Psychology, 8, 221-244.

Barker, J. B., Evans, A. L., Coffee, P., Slater, M. J., \& McCarthy, P. J. (2014). Consulting on tour: A dual-phase personal-disclosure mutual-sharing intervention and group functioning in elite youth cricket. The Sport Psychologist, 28, 186-197.

Bernier, M., Thienot, E. M. Cordon, R., \& Fournier, F. J. (2009). Mindfulness and acceptance approaches in sport performance. Journal of Clinical Sports Psychology, 4, 320-333.

Brawley L. R., Carron A. V., \& Widmeyer W. N. (1987). Assessing the cohesion of teams: Validity of the Group Environment Questionnaire. Journal of Sport Psychology, 9, 275294.

Brawley, L. R., Carron, A. V., \& Widmeyer, W. N. (1988). Exploring the relationship between cohesion and group resistance to disruption. Journal of Sport \& Exercise Psychology, 10(2), 199-213.

Brawley, L. R., \& Paskevich, D. M. (1997). Conducting team building research in the context of sport and exercise. Journal of Applied Sport Psychology, 9, 11-40. 
Brown K. W., \& Ryan R. M. (2003). The benefits of being present: Mindfulness and its role in psychological well-being. Journal of Personality and Social Psychology, 84, 822-848.

Canby, N. K., Cameron, I. M., Calhoun, A. T., \& Buchanan, G. M. (2015). A brief mindfulness intervention for healthy college students and its effects of psychological distress, selfcontrol, meta-mood, and subjective vitality. Mindfulness, 6, 1071-1081.

Carron A. V., Brawley, L. R., \& Widmeyer, W. N. (1998). Measurement of cohesion in sport and exercise. In J. L. Duda (Ed.), Advances in sport and exercise psychology measurement (pp. 213-226). Morgantown, WV: Fitness Information Technology.

Carron, A. V., Bray, S. R., \& Eys, M. A. (2002). Team cohesion and team success in sport. Journal of Sport Sciences, 20, 2, 119-126.

Carron A. V., Colman M. M., Wheeler J., \& Stevens D. (2002). Cohesion and performance in sport: A meta analysis. Journal of Sport \& Exercise Psychology, 24, 168-188.

Carron A. V., \& Eys, M. A. (2012). Group dynamics in sport (4th Ed.). Morgantown, WV. Fitness Information Technology.

Carron, A. V., \& Spink, K. S. (1993). Team building in an exercise setting. The Sport Psychologist, 7, 8-18.

Carron A. V., Widmeyer W. N., \& Brawley L. R. (1985). The development of an instrument to assess cohesion in sport teams: The group environment questionnaire. Journal of Sport Psychology, 7, 244-266.

Carson, J. W., Carson, K. M., Gil, K. M., \& Baucom, D. H. (2004). Mindfulness-based relationship enhancement. Behavior Therapy, 35, 471-494.

Cleirigh, D. O., \& Greaney, J. (2015). Mindfulness and group performance: An exploratory investigation into the effects of brief mindfulness intervention on group task 
performance. Mindfulness, 6, 601-609.

Compton, J., \& Compton, J. L. (2014). College sports, losing season, and image repair through open letters to fans. Communication \& Sport, 2, 345-362.

Crace, R. K., \& Hardy, C. J. (1997). Individual values in the team building process. Journal of Applied Sport Psychology, 9, 41-60.

Dryden W. (2006). Counselling in a nutshell. London, UK: Sage.

Dunn, J. G. H., \& Holt, N. L. (2004). A qualitative investigation of a personal-disclosure mutualsharing team building activity. The Sport Psychologist, 18, 363-380.

Dunlop, W. L., Falk, C. F., \& Beauchamp, M. R. (2013). How dynamic are exercise group dynamics? Examining changes in cohesion within class-based exercise programs. Health Psychology, 32, 1240-1243.

ESPN. (2007, December 1). Canadian colleges debating possibility of joining NCAA Division II ranks. https://www.espn.com/college-sports/news/story?id=3136704

Evans, A. L., Slatter, M. J., Turner, M. J., \& Barker, J. B. (2013). Using personal-disclosure mutual-sharing to enhance group functioning in a professional soccer academy. The Sport Psychologist, 27, 233-243.

Eys, M. A., \& Brawley, L. R. (2018). Reflections on cohesion research in sport and exercise groups. Social and Personality Psychology Compass, 12, 1-15.

Eys, M. A., Bruner, M. W., \& Martin, L. J. (2018). The dynamic group environment in sport and exercise. Psychology of Sport and Exercise, 42, 40-47.

Eys, M. A., Carron, A. V., Beauchamp, M. R., \& Bray, S. R. (2005). Athletes perceptions of the sources of role ambiguity. Small Group Research, 36, 383-403.

Gardner, F. L., \& Moore, Z. E. (2004). A mindfulness-acceptance-commitment-based approach 
to athletic performance enhancement: Theoretical considerations. Behavior Therapy, 35, 707-723.

Gooding, A., \& Gardner, F. L. (2009). An investigation of the relationship between mindfulness, preshot routine, and basketball free throw percentage. Journal of Clinical Sport Psychology, 4, 303-319.

Goodman, F. R., Kashdan, T. B., Mallard, T. T., \& Schumann, M. (2014). A brief mindfulness and yoga intervention with an entire NCAA division I athletic team: An initial investigation. Psychology of Consciousness: Theory, Research, and Practice, 1, 339-356.

Greeson, J. M., Juberg, M. K., Maytan, M., James, K., \& Rogers, H. (2014). A randomized controlled trial of Koru: A mindfulness program for college students and other emerging adults. Journal of American College Health, 62, 222-233.

Hirsch, S. (1992). MBTI team building program: Leader's resource guide. Consulting Psychologists Press, Inc., USA.

Holt, N. L., \& Dunn, J. G. H. (2006). Guidelines for delivering personal-disclosure mutualsharing team building interventions. The Sport Psychologist, 20, 348-367.

Ivarsson, A., Johnson, U., Andersen, M. B., Fallby, J., \& Altemyr, M. (2015). It pays to pay attention: A mindfulness-based program for injury prevention with soccer player. Journal of Applied Sport Psychology, 27, 319-334.

Jekauc, D., Kittler, C., \& Schlagheck, M. (2017). Effectiveness of a mindfulness-based intervention for athletes. Psychology, 8, 1-13.

John, S., Verma, S. K., \& Khanna, G. L. (2011). The effect of mindfulness meditation on the HPA-axis in pre-competition stress in sport performance of elite shooters. National Journal of Integrated Research in Medicine, 2, 15-21. 
472 Jones, N. M. P., Mellalieu, S. D., \& James, N. (2004). Team performance indicators as a function

473

474

475

476

477

478

479

480

481

482

483

484

485

486

487

488

489

490

491

492

493

494 of winning and losing in rugby union. International Journal of Performance Analysis in Sport, 4, 61-71.

Kabat-Zinn, J. (2003). Mindfulness-based interventions in context: Past, present, and future. Clinical Psychology: Science and Practice, 10, 144-156.

Kaufman, K. A., Glass, C. R., \& Pineau, T. R. (2018). Mindful sport performance enhancement: A mindfulness-based mental training program for athletes. Washington, DC: American Psychological Association.

Labelle, L. E., Campbell, T. S., Faris, P., \& Carlson, L. E. (2015). Mediators of mindfulnessbased stress reduction (MBSR): Assessing the timing and sequence of change in cancer patients. Journal of Clinical Psychology, 71, 21-40.

Leo, F. M., Gonzalez-Ponce, I., Sanchez-Miguel, P. A., Ivarsson, A., \& Garcia-Calvo, T. (2015). Role ambiguity, role conflict, team conflict, cohesion, and collective efficacy in sport teams: A multi-level analysis. Psychology of Sport and Exercise, 20, 60-66.

Li, G., Yuan, H., \& Zhang, W. (2016). The effects of mindfulness-based stress reduction for family caregivers: Systematic review. Archives of Psychiatric Nursing, 30, 292-299.

MacDonald, H. Z., \& Baxter, E. E. (2016). Mediators of the relationship between dispositional mindfulness and psychological well-being in female college students. Mindfulness, 8 , 398-407.

Martin, L. J., Bruner, M. W., Eys, M. A., \& Spink, K. S. (2014). The social environment in sport: selected topics. International Review of Sport and Exercise Psychology, 7, 87-105.

Martin, L. J., Carron, A. V., \& Burke, S. M. (2009). Team building interventions in sport: A meta-analysis. Sport and Exercise Psychology Review, 5, 3-18. 
Martin, L. J., Paradis, K. F., Eys, M. A., \& Evans, M. B. (2013). Cohesion in sport: New directions for practitioners. Journal of Sport Psychology in Action, 4, 14-25.

McEwan, D., \& Beauchamp, M. R. (2014). Teamwork in sport: a theoretical and integrative review. International Review of Sport and Exercise Psychology, 7, 229-250.

Pain, M., \& Harwood, C. (2009). Team building through mutual sharing and open discussion of team functioning. The Sport Psychologist, 23, 523-542.

Paradis, K. F., Carron, A. V., \& Martin, L. J. (2014a). Athlete perceptions of intragroup conflict in sport teams. Sport \& Exercise Psychology Review, 10, 4-18.

Paradis, K. F., Carron, A. V., \& Martin, L. J. (2014b). Development and validation of an inventory to assess conflict in sport teams: The Group Conflict Questionnaire. Journal of Sports Sciences, 32, 1966-1978.

Paradis, K. F., \& Loughead, T. M. (2012). Examining the mediating role of cohesion between athlete leadership and athlete satisfaction in youth sport. International Journal of Sport Psychology, 43, 117-136.

Paradis, K. F., \& Martin, L. J. (2012). Team building in sport: Linking theory and research to practical application. Journal of Sport Psychology in Action, 3, 159-170.

Paradis, K., Martin, L., \& Carron, A. (2012). Examining the relationship between passion and perceptions of cohesion in athletes. Sport \& Exercise Psychology Review, 8, 22-31.

Paskevich, D. M., Brawley, L. R., Dorsch, K. D., \& Widmeyer, W. N. (1999). Relationship between collective efficacy and team cohesion: Conceptual and measurement issues. Group Dynamics: Theory, Research, and Practice, 3, 210-222.

Remmers, C., Topolinski, S., \& Koole, S. L. (2016). Why being mindful may have more benefits 
than you realize: Mindfulness improves both explicit and implicit mood regulation. Mindfulness, 7, 829-837.

Rogers, H., \& Maytan, M. (2012). Mindfulness for the next generation: Helping emerging adults manage stress and lead healthier lives. New York: Oxford University Press.

521 Schumacker, R. E. (2016). Using $R$ with multivariate statistics. Thousand Oaks, CA: Sage.

522 Spink, K. S., Wilson, K. S., \& Odnokon, P. (2010). Examining the relationship between cohesion 523 and return to team in elite athletes. Psychology of Sport and Exercise, 11, 6-11.

524 Tziner, A., Nicola, N., \& Rizac, A. (2003). Relation between social cohesion and team performance in soccer teams. Perceptual and Motor Skills, 96, 145-148.

526 Widmeyer, W. N., \& Ducharme, K. (1997). Team building through team goal setting. Journal of $527 \quad$ Applied Sport Psychology, 9, 97-113.

528 Windsor, P. M., Barker, J., \& McCarthy, P. (2011). Doing sport psychology: Personal-disclosure mutual-sharing in professional soccer. The Sport Psychologist, 25, 94-114. 
Table 1

Overview of the Team Mindfulness Meditation Training Program

Week Mindfulness Meditation Skills

One

Two

Three

Four
- What is Mindfulness?

- $\quad$ Brief guided meditation (3 min)

- Continue with importance of mindfulness in sport and evidence behind it

- Conclude with guided meditation (10 min)

- 5-minute meditation

- Check-in

- Belly Breathing - Discuss how it is both involuntary and under the students' control, how it can reflect the students' mood and also be used to change their mood. (Each exercise includes:

Introduce, practice, feedback)

- Guided meditation - Body scan

- 5-minute meditation

- Check-in

- Dynamic Breathing (Chaotic Breathing) - Has its origins in yoga and is a powerful exercise for the students to use for immediate tension release and increased energy.

- Guided meditation - Gathas (strengthen the students' focus on their breath)

- 5-minute meditation

- Check-in 
- Walking meditation - The students can use it when they are too restless or anxious to sit still.

- Guided meditation - Labeling thoughts gives

Five students more help in working with their thoughts, as this is often the greatest obstacle for them.

- 5-minute meditation

- Check-in

- Guided Imagery - To calm the students, to change their mood, to take a vacation in their minds or prepare for a game.

- Guided meditation - Labeling feelings

Six

- 5-minute meditation

- Check-in

- Mindful eating - A skill that students can use to enhance their pleasure in eating, as well as their ability to return their minds to the present moment.

- Guided meditation - Body scan

Seven

- 5-minute meditation

- Check-in

- Labeling thoughts and feelings

- Guided meditation - Gathas

Eight

- 5-minute meditation

- Check-in

- Next steps for the students and developing their own meditation practice. 
Table 2

Descriptive Statistics for Cohesion at Time 1 (Baseline) and Time 2 (Post-Intervention)

\begin{tabular}{lcccccc}
\hline \multicolumn{2}{c}{ Time 1} & \multicolumn{5}{c}{ Time 2} \\
\hline Variable & Intervention & Control & & Intervention & Control \\
& $M(S D)$ & $M(S D)$ & $\alpha$ & $M(S D)$ & $M(S D)$ & $\alpha$ \\
\hline ATG-T $^{\mathrm{a}}$ & $7.94(1.11)$ & $7.62(1.70)$ & .80 & $5.76(1.98)$ & $5.64(1.73)$ & .82 \\
ATG-S $^{\mathrm{a}}$ & $6.76(1.48)$ & $7.21(1.70)$ & .85 & $7.51(0.99)$ & $6.20(2.13)$ & .84 \\
GI-T $^{\mathrm{a}}$ & $6.34(1.01)$ & $5.84(1.24)$ & .82 & $4.91(1.20)$ & $4.25(1.00)$ & .81 \\
& & & & & & \\
GI-S $^{\mathrm{a}}$ & $6.55(1.37)$ & $6.36(1.06)$ & .81 & $6.35(1.13)$ & $5.02(0.96)$ & .81 \\
& & & & & & \\
\hline
\end{tabular}

Note. ATG-T = Individual Attractions to the Group - Task; ATG-S = Individuals Attractions to the Group - Social; GI-T = Group Integration - Task; GI-S = Group Integration - Social.

${ }^{\text {a }}$ Assessed on a 9-point scale ranging from 1 to 9 with higher scores representing stronger perceptions of cohesion. 
Table 3

Bivariate Correlations for Cohesion at Time 1 (Baseline) and Time 2 (Post-Intervention) Variable 2

3

\section{$\underline{\text { Time } 1}$}

1. ATG-T

$.46 * *$

$.65^{* *}$

$.62 * *$

2. ATG-S

$\begin{array}{ll}- & .13\end{array}$

.31

3. GI-T

$-\quad .76^{* *}$

4. GI-S

Time 2

1. ATG-T

.14

$.49 * *$

$.56^{* *}$

2. ATG-S

$\begin{array}{ll}- & .19\end{array}$

.29

3. GI-T

$-.67 * *$

4. GI-S

Note. ATG-T = Individual Attractions to the Group - Task; ATG-S = Individuals Attractions to the Group - Social; GI-T = Group Integration - Task; GI-S = Group Integration - Social. **Significant at the .01 level. 